\title{
СПОСОБ ЛЕЧЕНИЯ МЕХАНИЧЕСКОЙ ЖЕЛТУХИ ОТРИЦАТЕЛЬНЫМИ АЭРОИОНАМИ
}

\section{METHOD FOR TREATMENT OF MECHANICAL JARCUS WITH NEGATIVE AEROIONS}

\section{E. Boyarkin \\ A. Belyaev \\ N. Bespalov \\ P. Parkin \\ D. Babas \\ A. Majorov}

Summary. Objective: to develop a technology for the treatment of mechanical jaundice with negative aeroions.

Materials and methods: 20 laboratory animals (mature male rats of the Vinar series with an average body weight of $200-250 \mathrm{~g}$ ) were used in the experiment, divided into 2 groups: experimental -15 and control 5 individuals, respectively. Surgical treatment for the creation of reversible mechanical jaundice was performed under thiopentalsodium anesthesia. A day after the operation, the experimental group of animals was exposed to the general effect of negative aeroions for 30 calendar days of observation. Decompression of choledochus (resolution of mechanical jaundice) was performed on the 3rd day after surgery. During the experiment, the general condition of the animals was evaluated daily (behavior, reflexes, skin color, the condition of the postoperative wound), in order to control functional disorders of the liver, venous blood was taken from the tail vein for biochemical analysis (total bilirubin, alanine aminotransferase (AIAT), alkaline phosphatase (ALP), catalase). The deficit in the volume of circulating blood was compensated by bolus injection of an isotonic sodium chloride solution in an average dosage of $0.1 \mathrm{ml} / \mathrm{kg}$ of animal body weight into the tail vein.

Results: positive results of the use of mechanical jaundice therapy with negative aeroions were obtained.

Conclusion: negative aeroionotherapy provides antioxidant protection of hepatocytes in cytolytic syndrome caused by mechanical obstruction of the biliary system, accelerates the regeneration of tissues of postoperative wounds.

Keywords: obstruction of the biliary system, negative aeroion therapy, lipid peroxidation.
Бояркин Евгений Викторович

Аспирант, ФГБОУ ВО «Национальный исследовательский Мордовский государственный университет им. Н.П. Огарева» boyarkin_ev@mail.ru

Беляев Александр Назарович Д.м.н., профессор, ФГБОУ ВО «Начиональный исследовательский Мордовский государственный университет им. Н.П. Огарева»

belyaevan@mail.ru

Беспалов Николай Николаевич

К.т.н., дочент, ФГБОУ ВО «Национальный исследовательский Мордовский государственный университет им. Н.П. Огарева»

2243705@mail.ru

Паркин Павел Николаевич

ФГБОУ ВО «Национальный исследовательский Мордовский государственный университет им. Н.П. Огарева» parkin.p2000@yandex.ru

Бабась Денис Владимирович ГБУЗ РМ «МРЦКБ», Саранск doctor_08@inbox.ru

Майоров Алексей Валентинович К.м.Н., ГБУЗ РМ «МРЦКБ», СаранСК fleshmen@mail.ru

Аннотация. Цель исследования: разработка технологии лечения механической желтухи отрицательными аэроионами.

Материалы и методы: в эксперименте было использовано 20 лабораторных животных (половозрелые крысы мужского пола серии Винар со средней массой тела 200-250 гр), разделенных на 2 группы: опытная - 15 и контрольная - 5 особей соответственно. Оперативное лечение по созданию обратимой механической желтухи производилось под тиопентал-натриевым наркозом. Через сутки после операции опытная группа животных подвергалась общему воздействию отрицательных аэроионов на протяжении 30-ти календарных дней наблюдения. Декомпрессия холедоха (разрешение механической желтухи) проводилась на 3-и сутки после операции. На протяжении эксперимента ежедневно оценивалось общее состояние животных (поведение, рефлексы, окраска кожных покровов, состояние послеоперационной раны), с целью контроля за функциональными нарушениями печени производился забор венозной крови из хвостовой вены для биохимического анализа (общий билирубин, аланиновая аминотрасфераза (АлАТ), щелочная фосфатаза (ЩФ), каталаза). Дефицит объема циркулирующей крови восполняли болюсным введением изотонического раствора натрия хлорида в средней дозировке 0,1 мл/кг массы тела животного в вену хвоста. 


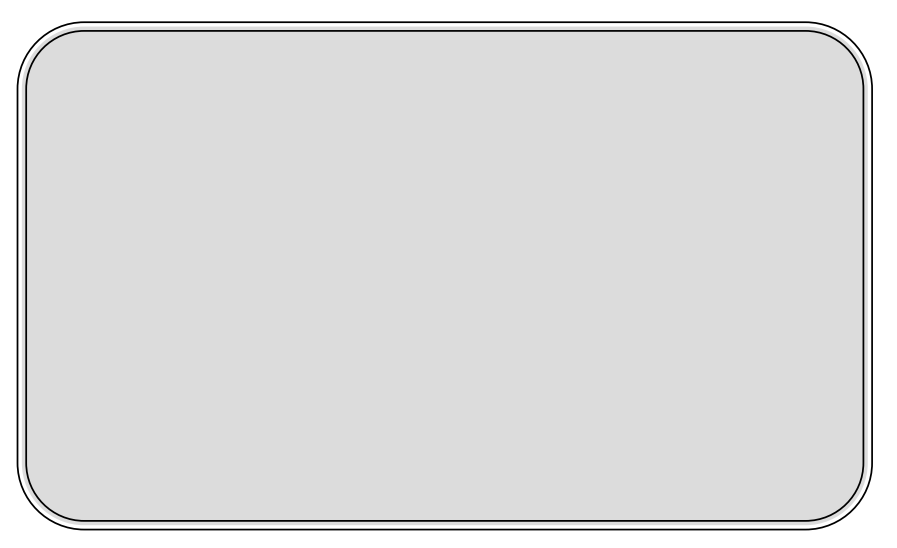

\section{Введение}

бструкция желчевыводящей системы с последующей гипертензией протоков обуславливает развитие печеночно-клеточной недостаточности и является одной из наиболее частых причин патологии гепатобилиарной зоны [1].

Помимо хирургического лечения причин механической желтухи широко применяется способ системной метаболической коррекции функциональных нарушений печени путем внутривенных капельных и болюсных введений лекарственных средств (антибактериальные препараты, гепатопротекторы, витамины, антиоксиданты). Известно, что при механической желтухе за счет активации процесса оксидативного стресса усиливается механизм перекисного окисления липидов, приводящий к цитолизу гепатоцитов.

Антиоксидантное действие электрических зарядов воздуха на клетки организма человека было доказано еще в 1918 году А.Л. Чижевским (1897-1964). Отрицательно заряженный ионизированный воздух на протяжении десятков лет широко используется в клинической медицине при заболеваниях различных органов и систем. Известны основные показания к применению отрицательной аэроионотерапии, среди которых встречаются патологии органов дыхательной, сердечно-сосудистой и нервной систем, поражение кожных покровов [2]. В современных источниках литературы не указаны попытки применения отрицательной аэроионотерапии при заболеваниях пищеварительной системы (в частности, механической желтухе при желчекаменной болезни).

Моделирование обратимой механической желтухи у лабораторных животных производилось путем наложения на общий желчный проток петли-удавки согласно описанной методике [4]. Декомпрессия холедоха (удаление петли-удавки) осуществлялась на 3-и сутки после моделирования.
Результаты: получены положительные результаты применения терапии механической желтухи отрицательными аэроионами.

Вывод: отрицательная аэроионотерапия оказывает антиоксидантную защиту гепатоцитов при цитолитическом синдроме, вызванном механической обструкцией желчевыводящей системы, способствует ускорению регенерации тканей послеоперационных ран.

Ключевые слова: обструкция желчевыводящей системы, отрицательная аэроионотерапия, перекисное окисление липидов.

\section{Шель исслеАования}

Разработка технологии лечения механической желтухи отрицательно заряженными аэроионами.

\section{Материалы и методы}

Научно-исследовательская работа проводилась в условиях экспериментально-биологической клиники (виварии) при Медицинском институте «МГУ им. Н.П. Огарева» с учетом заключения ЛЭК.

В работе было использовано 20 половозрелых особей крыс-самцов серии Винар со средней массой тела 200-250 гр. Животные прошли недельный карантин и профилактические прививки. Все животные имели свободный доступ к пище и воде.

Экспериментальные животные были разделены на группы: опытная - 15 и контрольная - 5 особей соответственно. Оперативное пособие (моделирование обратимой механической желтухи) проводилось под тиопентал-натриевым наркозом в дозировке 0,1 мл. на 100 гр. массы тела животного однократным внутримышечным введением в наружную поверхность бедра. С учетом анатомо-физиологических особенностей выбором оперативного доступа стала верхняя срединная лапаротомия. Обратимая механическая желтуха создана наложением петли-удавки на дистальный отдел холедоха, свободный конец последней выведен через контрапертуру и зафиксирован узловым швом (хирургической нитью ПГА (полигидроксиацетил) 00)) к холке животного. На 3-и сутки эксперимента произведена декомпрессия холедоха путем удаления петли-удавки.

Спустя сутки после операции животных опытной группы (15 особей) помещали в специализированную клетку со встроенным в металлическую крышку-решетку источником отрицательных аэроионов. На протяжении 20 календарных дней прооперированных животных подвергали общему воздействию отрицательно 
Таблица 1. Оценка общего состояния лабораторных животных контрольной группы в послеоперационном периоде

\begin{tabular}{|c|c|c|c|}
\hline \multirow{2}{*}{ Показатель } & \multicolumn{3}{|c|}{ Период послеоперационного наблюдения (дней) } \\
\hline & 3 & 10 & 15 \\
\hline Уровень сознания & Ясное & ЯсHOe & Яchoe \\
\hline $\begin{array}{l}\text { Характер питания, состояние } \\
\text { послеоперационной раны }\end{array}$ & Без особенностей & $\begin{array}{l}\text { Умеренное снижение } \\
\text { массы тела на 10-15 гр. } \\
\text { Послеоперационная рана } \\
\text { без особенностей, швы лежат } \\
\text { хорошо }\end{array}$ & $\begin{array}{l}\text { Восполнение дефицита массы } \\
\text { тела до исходных значений. } \\
\text { Послеоперационная рана без } \\
\text { особенностей (заживление } \\
\text { первичным натяжением), швы } \\
\text { удалены на 10-е сутки после } \\
\text { операции }\end{array}$ \\
\hline $\begin{array}{l}\text { Поведение, рефлексы } \\
\text { (поисковый, оборонительный) }\end{array}$ & $\begin{array}{l}\text { Умеренное снижение } \\
\text { двигательной активности, } \\
\text { рефлексов }\end{array}$ & $\begin{array}{l}\text { Отмечается незначительное } \\
\text { снижение двигательной } \\
\text { активности. Рефлексы } \\
\text { сохранены. }\end{array}$ & Активное, рефлексы сохранены. \\
\hline $\begin{array}{l}\text { Цвет кожных покровов (уши, } \\
\text { хвост) }\end{array}$ & $\begin{array}{l}\text { Физиологическая окраска } \\
\text { кожных покровов }\end{array}$ & $\begin{array}{l}\text { Умеренная желтушность кожи } \\
\text { ушей и хвоста. }\end{array}$ & $\begin{array}{l}\text { Физиологическая окраска } \\
\text { кожных покровов. }\end{array}$ \\
\hline
\end{tabular}

Таблица 2. Оценка общего состояния лабораторных животных опытной группы в послеоперационном периоде

\begin{tabular}{|c|c|c|c|}
\hline \multirow{2}{*}{ Показатель } & \multicolumn{3}{|c|}{ Период послеоперационного наблюдения (дней) } \\
\hline & 3 & 10 & 15 \\
\hline Уровень сознания & Ясное & Ясное & Ясное \\
\hline $\begin{array}{l}\text { Характер питания, состояние } \\
\text { послеоперационной раны }\end{array}$ & $\begin{array}{l}\text { Питание не нарушено. } \\
\text { Послеоперационная рана без } \\
\text { признаков воспаления, швы } \\
\text { лежат хорошо }\end{array}$ & $\begin{array}{l}\text { Питание не нарушено. } \\
\text { Послеоперационная рана } \\
\text { зажила первичным натяжением } \\
\text { (швы удалены на 5-е сутки } \\
\text { после операции). }\end{array}$ & $\begin{array}{l}\text { Питание не нарушено. } \\
\text { На месте оперативного } \\
\text { вмешательства имеется } \\
\text { послеоперационный рубец. }\end{array}$ \\
\hline $\begin{array}{l}\text { Поведение, рефлексы } \\
\text { (поисковый, оборонительный) }\end{array}$ & $\begin{array}{l}\text { Умеренное снижение } \\
\text { двигательной активности } \\
\text { и рефлексов }\end{array}$ & $\begin{array}{l}\text { Отмечается гиперактивное } \\
\text { поведение животных } \\
\text { (ускорение передвижения } \\
\text { внутри клеток, резкое } \\
\text { выражение оборонительного } \\
\text { рефлекса) }\end{array}$ & $\begin{array}{l}\text { Гиперактивное, рефлексы } \\
\text { сохранены }\end{array}$ \\
\hline $\begin{array}{l}\text { Цвет кожных покровов (уши, } \\
\text { хвост) }\end{array}$ & $\begin{array}{l}\text { Физиологическая окраска } \\
\text { кожных покровов }\end{array}$ & $\begin{array}{l}\text { Умеренная желтушность кожи } \\
\text { ушей и хвоста. }\end{array}$ & $\begin{array}{l}\text { Физиологическая окраска } \\
\text { кожных покровов. }\end{array}$ \\
\hline
\end{tabular}

заряженными аэроионами в дозировке 10 тыс. аэроионов в 1 см $^{3}$ с экспозицией 60 мин. Прооперированные животные контрольной группы оставались интактными после операции.

За прооперированными лабораторными животными наблюдали на протяжении 20 календарных дней. По истечении срока наблюдения животных выводили из эксперимента с помощью летальных доз анестетиков.

Оценку общего состояния прооперированных животных обеих групп проводили на 3, 10 и 15-е сутки послеоперационного периода: характер питания (путем взвешивания), поведения и рефлексов, двигательную активность, окраску кожных покровов (уши, хвост), состояние послеоперационной раны (таб. 1). С целью контроля за функциональной активностью печени в те же сроки производился забор венозной крови из хвостовой вены для биохимического анализа (общий билирубин, аланиновая аминотрансфераза (АлАТ), щелочная фосфатаза (ЩФ), каталаза) (таб. 2). Определение показателей биохимического анализа крови проводили стандартными методами на анализаторе Dixion Topys 1230.

Результаты биохимического анализа крови обработаны с помощью программы «Statictica 8,0» на абсолютное значение выборочной разницы между показателями биохимического анализа крови (общий билирубин, АлАТ, ЩФ, каталаза) в сравниваемых группах после опе- 
Таблица 3. Средние значения показателей биохимического анализа крови у прооперированных лабораторных животных опытной и контрольной групп

\begin{tabular}{|c|c|c|c|c|c|}
\hline \multirow[b]{2}{*}{ Группа животных } & \multirow[b]{2}{*}{$\begin{array}{l}\text { День забора } \\
\text { крови* после } \\
\text { операции }\end{array}$} & \multicolumn{4}{|c|}{ Показатели биохимического анализа крови } \\
\hline & & $\begin{array}{l}\text { Общий билирубин } \\
\text { (мкмоль/л) }\end{array}$ & $\begin{array}{l}\text { Аланиновая } \\
\text { аминотрансфераза } \\
\text { (АлАТ) (Ед/л) }\end{array}$ & $\begin{array}{l}\text { Щелочная } \\
\text { фосфатаза (ЩФ) } \\
\text { (Ед/л) }\end{array}$ & $\begin{array}{l}\text { Каталаза (Ед/ } \\
\text { мл) }\end{array}$ \\
\hline \multirow{6}{*}{ Опытная } & \multirow{2}{*}{3} & $4,7 \pm 0,3$ & $122,1 \pm 1,2$ & $361,2 \pm 2,1$ & $12,8 \pm 0,6$ \\
\hline & & $p>0,05$ & $p>0,05$ & $p>0,05$ & $p<0,05$ \\
\hline & \multirow{2}{*}{10} & $2,6 \pm 0,8$ & $106,3 \pm 1,1$ & $337,4 \pm 1,6$ & $16,2 \pm 0,8$ \\
\hline & & $p<0,05$ & $p<0,05$ & $p>0,05$ & $p<0,05$ \\
\hline & \multirow{2}{*}{15} & $1,1 \pm 1,0$ & $93,5 \pm 0,8$ & $295,2 \pm 1,3$ & $11,7 \pm 0,5$ \\
\hline & & $p<0,05$ & $p<0,05$ & $p<0,05$ & $p<0,05$ \\
\hline \multirow{3}{*}{ Контрольная } & 3 & $4,5 \pm 0,6$ & $126,3 \pm 0,9$ & $348,2 \pm 1,6$ & $14,1 \pm 0,7$ \\
\hline & 10 & $2,8 \pm 0,8$ & $116,4 \pm 1,0$ & $327,6 \pm 1,2$ & $18,6 \pm 0,9$ \\
\hline & 15 & $1,3 \pm 0,7$ & $95,1 \pm 0,7$ & $309,5 \pm 1,0$ & $17,4 \pm 0,6$ \\
\hline
\end{tabular}

Примечение: * — венозная кровь из хвостовой вены; р — достоверность по отношению к контролю

\section{Средние значения концентрации общего билирубина в плазме крови}

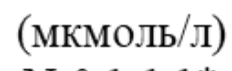

$\mathrm{N}-0,1-1,1^{*}$

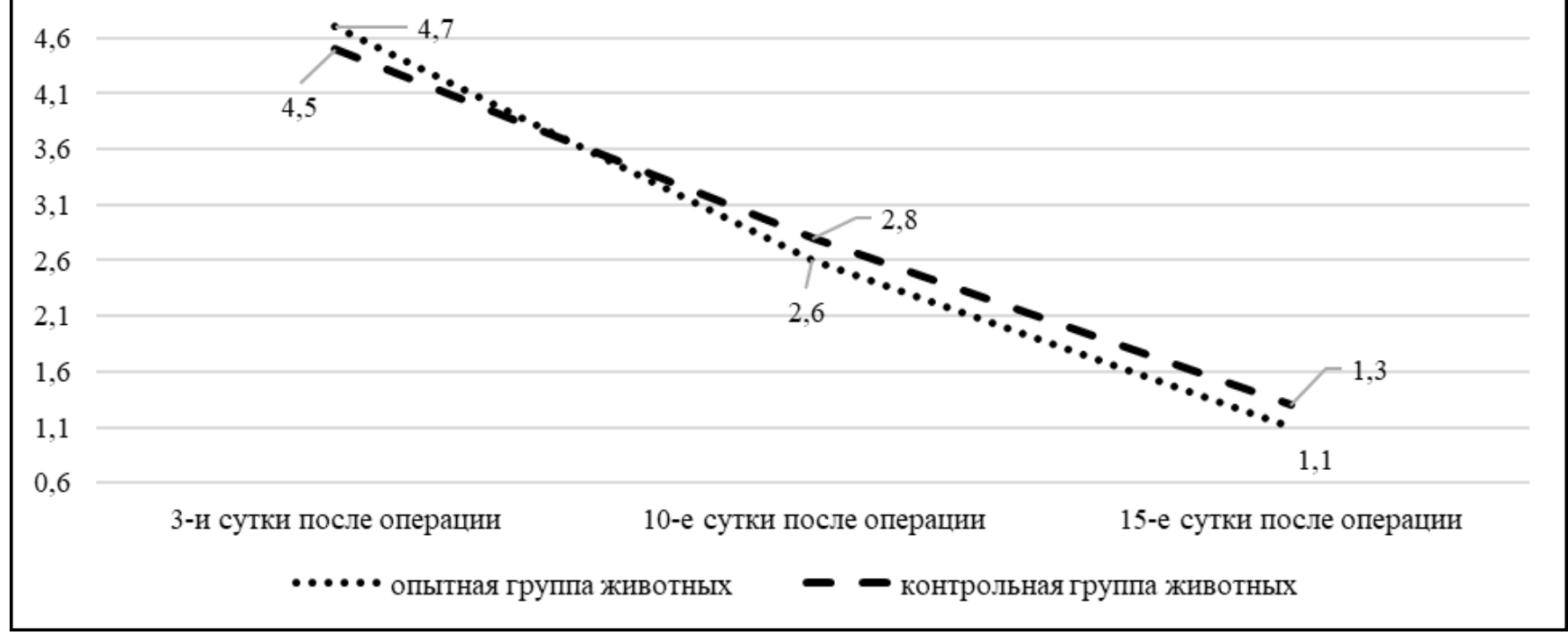

Рис. 1. Средние значения концентрации общего билирубина в плазме крови прооперированных лабораторных животных опытной и контрольной групп

Примечание: $\mathrm{N}^{*}$ - референсные значения 


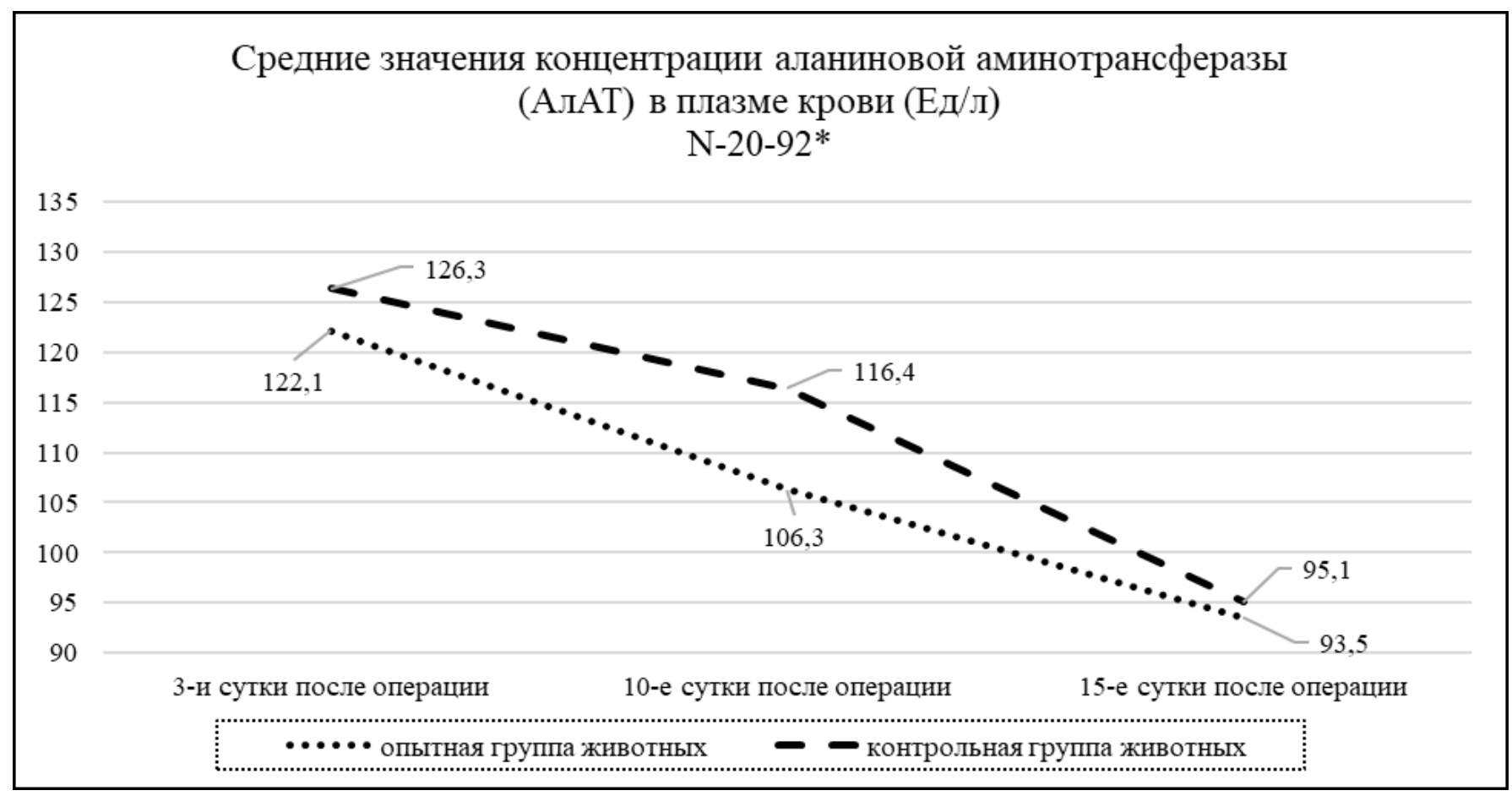

Рис. 2. Средние значения концентрации аланиновой аминотрансферазы (АлАТ) в плазме крови прооперированных лабораторных животных опытной и контрольной групп

Примечание: $\mathrm{N}^{*}$ - референсные значения

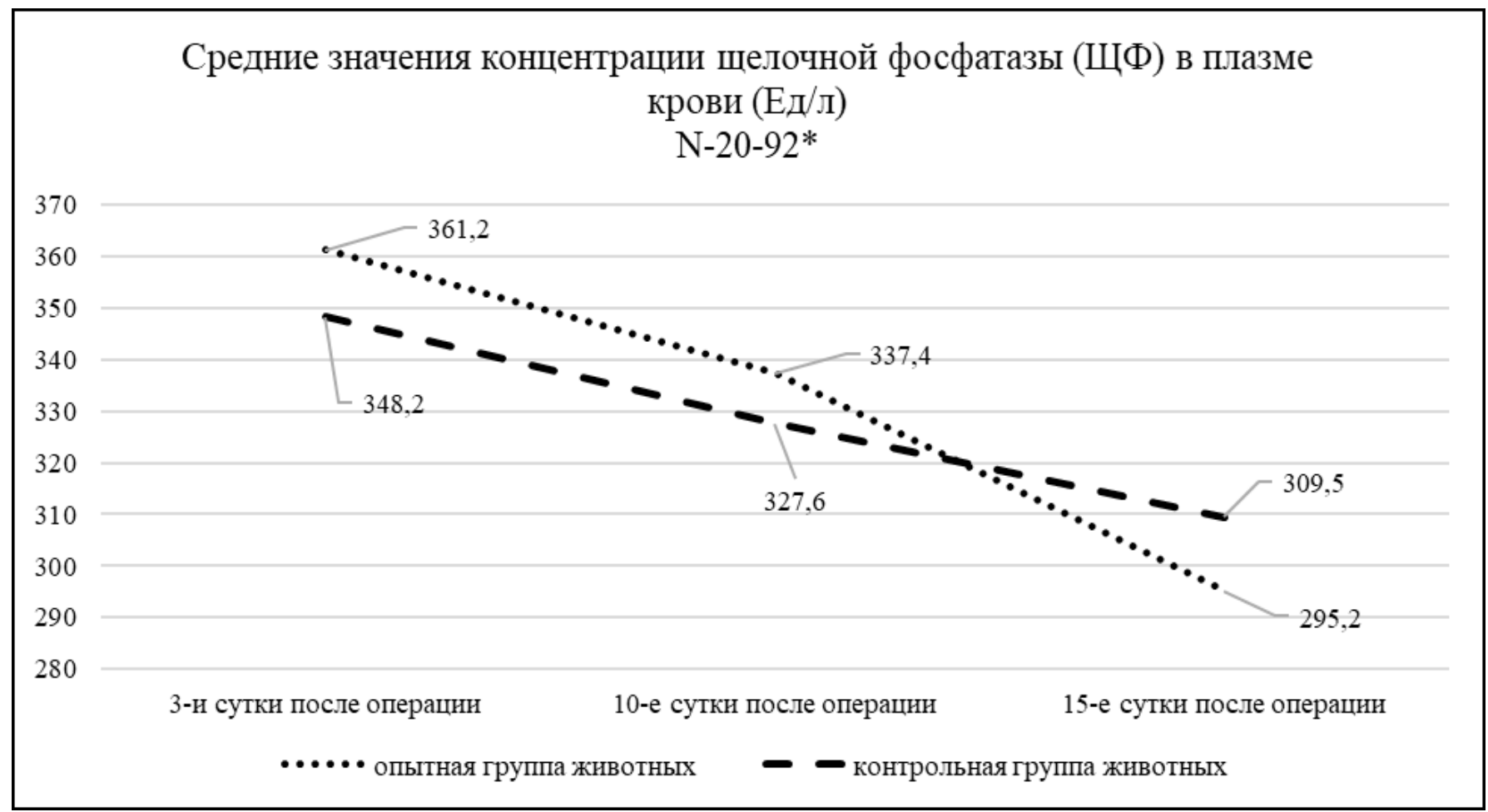

Рис. 3. Средние значения концентрации щелочной фосфатазы (ЩФ) в плазме крови прооперированных лабораторных животных опытной и контрольной групп.

Примечание: $\mathrm{N}^{*}$ - референсные значения 


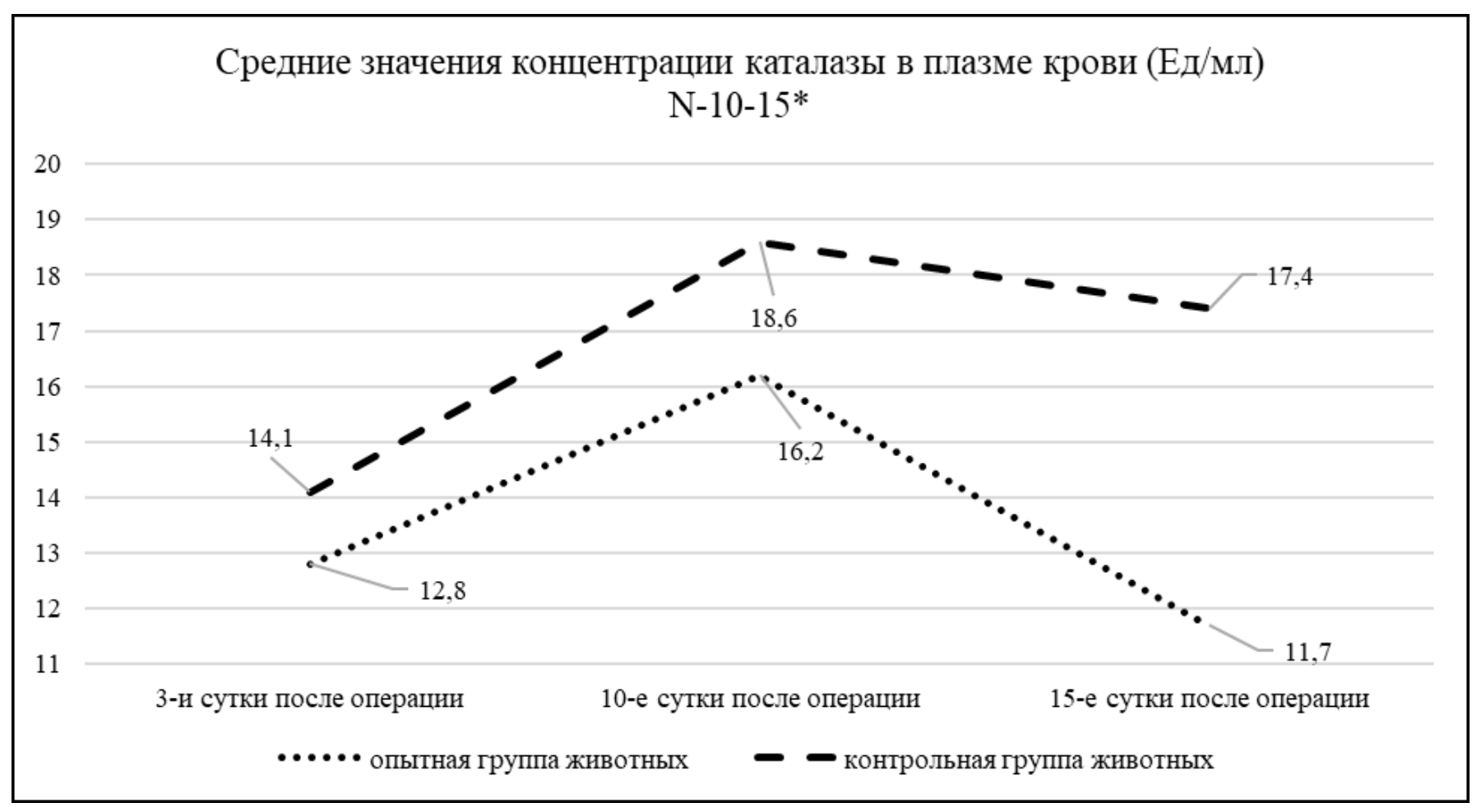

Рис. 4. Средние значения концентрации каталазы в плазме крови прооперированных лабораторных животных опытной и контрольной групп.

Примечание: $\mathrm{N}^{*}$ - референсные значения

ративного пособия на 3, 10 и 15-е сутки послеоперационного периода.

\section{Результаты и обсужАение}

Показатели оценки общего состояния прооперированных лабораторных животных контрольной группы представлены в таблице 1.

Показатели оценки общего состояния прооперированных лабораторных животных опытной группы представлены в таблице 2.

Средние значения показателей биохимического анализа крови экспериментальных животных обеих групп в процессе динамического наблюдения представлены в таблице 3, сравнительная характеристика в контрольной и опытной группах на графиках 1-4.

При анализе полученных данных установлено, что концентрация общего билирубина в опытной группе сохраняла стойкую тенденцию к понижению по сравнению с контрольной группой. Анализируемый показатель был достоверно ниже на 10-е и 15-е сутки исследования на 7,1 и $15,4 \%$ соответственно ( $<<0,05)$. (см. рис. 1)
Концентрация аланиновой аминотрансферазы имела схожую динамику. Данный показатель в опытной группе (относительно контроля) был достоверно ниже на тех же сроках на 8,8 и $1,7 \%$ соответственно $(p<0,05)$. (см. рис. 2)

Щелочная фосфатаза в опытной группе была достоверно ниже относительно контрольной лишь на 15-е сутки наблюдения на 4,6\% (p<0,05). (см. рис. 3)

Во все контрольные дни в опытной группе отмечена стойкая динамика понижения уровня каталазы в крови исследуемых относительно контроля. Показатель был достоверно ниже на третьи, десятые, и, затем, на пятнадцатые сутки наблюдения на 9,2, 12,9 и 32,8\% соответственно ( $p<0,05)$. (см. рис. 4)

В ходе проведенного экспериментального исследования установлено положительное влияние отрицательной аэроионотерапии при лечении обратимой механической желтухи у лабораторных животных.

Анализ проделанной научно-исследовательской работы показал активное участие отрицательно заряженных аэроионов в поведенческой сфере экспери- 
ментальных животных (уменьшение сроков послеоперационной реабилитации), ускорении заживления послеоперационной раны, метаболических процессов в местных тканях в виде быстрого заживления послеоперационной раны во время проведения эксперимента на лабораторных животных с обратимой механической желтухой нами не выявлено побочных эффектов от проводимых регионарных инфузий: на 15-е сутки послеоперационного периода отмечается уменьшение признаков печеночной энцефалопатии в виде восстановления сознания и нормализации рефлексов, восполнение дефицита массы тела (разница от исходных величин оценивалась путем взвешивания животных на 5, 10 и 15-е сутки послеоперационного периода), купирование явлений желтухи (физиологическая окраска кожи ушей и хвоста).

\section{Зак^ючение}

Катетеризация воротной вены печени у лабораторных животных (крыс) дает возможность проведения внутрипортального введения лекарственных средств при патологии гепатобилиарной зоны. Регионарная терапия предусматривает адресную доставку действующих веществ к очагу поражения, обеспечивает точную коррекцию дозировки вводимых препаратов и минимизацию побочных эффектов, характерных для системного применения лекарственных средств. Во время эксперимента нами не выявлено осложнений от проведенной катетеризации портальной вены в течение 20-ти дней наблюдений. Исходя из этого, использование данного метода возможно в течение длительного времени.

\section{ЛИТЕРАТУРА}

1. Ветшев П.С. Механическая желтуха: причины и диагностические подходы / П.С. Ветшев // Анналы хирургической гепатологии. - 2011.- Т. 16, № 3,- C. 50-57. https://doi.org/10.16931/1995-5464.2015359-67

2. Беляев, А.Н., Беляев, С.А., Костин, С.В., Хвостунов, С.И., Елистратов, Ю.В., Церковнов С.С. (2012). Интенсивная терапия печеночной недостаточности при механической желтухе. Медицинский альманах, (2).- С. 167-170.

3. Журнал Русской Физической Мысли, 2014, № 1-12, стр. 125

4. Беляев А.Н. Эффективность внутрипортальных инфузий мексидола при лечении механической желтухи. Журнал «Хирургия» № 9, 2009 , стр. 66-69.

5. Бекбауов С.А. Современные подходы диагностики и лечения печеночно-почечной недостаточности у больных механической желтухой / С.А. Бекбауов, Е.М. Липницкий, А.Е. Котовский, В.Г. Истратов // Вестник Национального медико-хирургического Центра им. Н.И. Пирогова.— 2013.- Т. 8 , № 2. - C. 76-78.

6. Воротынцев А.С. Современные представления о диагностике и лечении желчнокаменной болезни и хронического калькулезного холецистита / А.С. Воротынцев // Лечащий врач. — 2012.— № 07/12.

7. Рогальский А.В.Эффективность озонотерапии в комплексном лечении механической желтухи: Автореф. дисс. ... канд. мед. наук.- Бишкек, 2011. - $24 \mathrm{C}$.

8. Трегубова Н.В. Возрастные изменения прооксидантного - антиоксидантного баланса при оксидативном стрессе / Н.В. Трегубова, И.С. Исмаилов // Вестник АПК Ставрополья. — 2012. — № 3.- С. 142-148.

9. Copple B.L. Hypoxia-Inducible Factor Activationin Myeloid Cells Contributes to the Development of Liver Fibrosisin Cholestatic Miceophia / B.L. Copple, S. Kaska, C. Wentling// J. Pharmacol. Exp.Ther. - 2012. — Vol. 341. — P. 307-316.

10. Damnjanović Z. Correlation of inflammation parameters and biochemical markers of cholestasis with the intensity of lipid peroxidation in patients with choledocholithiasis / Z. Damnjanović, M. Jovanović, A. Nagorni, M. Radojković // Vojnosanit Pregl. — 2013. — Vol. 70(2). — P. 170-6.

( Б Бояркин Евгений Викторович ( boyarkin_ev@mail.ru ), Беляев Александр Назарович ( belyaevan@mail.ru ), Беспалов Николай Николаевич ( 2243705@mail.ru ), Паркин Павел Николаевич ( parkin.p2000@yandex.ru ), Бабась Денис Владимирович ( doctor_08@inbox.ru ), Майоров Алексей Валентинович ( fleshmen@mail.ru ). Журнал «Современная наука: актуальные проблемы теории и практики» 